\title{
DESEMPENHO AGRONÔMICO DA ALFACE CRESPA A PARTIR DE MUDAS PRODUZIDAS COM GONGOCOMPOSTO
}

\author{
Luiz Fernando de Sousa Antunes ${ }^{1}$, Rafael Nogueira Scoriza², Emmeline Machado França ${ }^{3}$, Dione \\ Galvão da Silva ${ }^{4}$, Maria Elizabeth Fernandes Correia ${ }^{5}$, Marco Antonio de Almeida Leal ${ }^{5}$, Janaina \\ Ribeiro Costa Rouws ${ }^{5}$
}

\begin{abstract}
RESUMO - Sendo o gongocomposto pouco conhecido, é de grande valia avaliar sua eficiência na produção de mudas. O objetivo deste trabalho foi avaliar o desempenho agronômico da alface cultivar Vera sob sistema de produção orgânico, de acordo com a qualidade das mudas produzidas a partir de gongocompostos. O delineamento experimental foi em blocos casualizados com quatro repetições e quatro tratamentos, constituídos por mudas de alface desenvolvidas em quatro tipos de substratos: gongocomposto de 90 dias (T1); gongocomposto de 125 dias (T2); gongocomposto de 180 dias (T3) e substrato SIPA (T4). Aos 28 dias após a semeadura avaliou-se o vigor da muda e estabilidade do torrão e aos 42 dias após o transplantio, avaliou-se a massa fresca comercial $(\mathrm{g})$, o diâmetro e altura da planta $(\mathrm{cm})$, número de folhas maiores que cinco centímetros, classe comercial e produtividade. $\mathrm{O}$ tratamento $\mathrm{T} 1$ apresentou resultados inferiores quando comparado aos demais tratamentos avaliados, porém sua produtividade atende à esperada para o estado do Rio de Janeiro. Os demais tratamentos, mesmo não diferindo entre si estatisticamente, apresentaram diferença na produtividade estimada, com 10,38 e 11,82\% menor para o tratamento $\mathrm{T} 2$ em relação aos tratamentos $\mathrm{T} 3$ e T4, respectivamente, demonstrando que o gongocomposto pode ser aproveitado na formação de mudas de alface de superior qualidade, sendo capaz de influenciar diretamente na produtividade da cultura da alface.
\end{abstract}

Palavras chave: adubação orgânica, Lactuca sativa L., substratos.

\section{AGRONOMIC PERFORMANCE OF LETTUCE CULTIVATE VERA FROM SEEDLINGS PRODUCED FROM MILLICOMPOST}

\begin{abstract}
As the millicompost is little known, it is of great value to evaluate its efficiency in the production of seedlings. The objective of this work was to evaluate the agronomic performance of lettuce cultivate Vera under organic production system, according to the quality of the seedlings produced from millicompost. The experimental design was a randomized block with four replicates and four treatments, consisting of lettuce seedlings developed in four types of substrates: 90 days millicompost (T1); 125 days millicompost (T2); 180 days millicompost (T3) and substrate SIPA (T4). At 28 days after sowing the vigor of the seedling and stability of the clod were evaluated and at 44 days after transplanting, commercial fresh mass ( $\mathrm{g}$ ), plant diameter and height $(\mathrm{cm})$, number of large leaves which five centimeters, commercial grade and productivity. The $T 1$ treatment presented lower results when compared to the other treatments evaluated, but its productivity meets the expectations for the state of Rio de Janeiro. The other treatments, even though they did not differ
\end{abstract}

\footnotetext{
${ }^{1}$ Biólogo e Engenheiro Agrônomo; Mestre em Agronomia - Ciência do Solo; Doutorando do Programa de Pós-graduação em Fitotecnia pela UFRRJ (Bolsista CAPES); E-mail: fernando.ufrrj.agro@gmail.com;

${ }^{2}$ Biólogo; Doutor em Ciência do Solo (UFRRJ);

${ }^{3}$ Engenheira Agrônoma (UFV);

${ }^{4}$ Engenheira Agrônoma (UFRRJ); Analista da Embrapa Agrobiologia;

${ }^{5}$ Bióloga (UFRJ); Pesquisadora da Embrapa Agrobiologia;

${ }^{5}$ Engenheiro Agrônomo (UFRRJ); Pesquisador da Embrapa Agrobiologia;

${ }^{5}$ Engenheira Agrônoma (UFLA); Pesquisadora da Embrapa Agrobiologia.
} 
statistically, presented a difference in the estimated productivity, with 10.38 and $11.82 \%$ lower for the T2 treatment in relation to the T3 and T4 treatments, respectively, demonstrating that the millicompost can be used in the formation of lettuce seedlings of superior quality, being able to directly influence in the productivity of the lettuce crop.

Keywords: Lactuca sativa L., organic fertilization, substrates.

\section{INTRODUÇÃO}

A alface (Lactuca sativa L.) é a hortaliça folhosa mais consumida in natura no mundo e a mais cultivada em sistemas orgânicos (Hernandez et al., 2013). Com isso torna-se estratégico produzir mudas desta hortaliça com alta qualidade para obter resultados satisfatórios a nível de produção em campo (Diniz et al., 2006). Para tanto, é necessário o emprego de substratos de qualidade, que promovam o melhor crescimento e desenvolvimento inicial às mudas de hortaliças. A fase de produção de mudas é onde ocorre a definição do potencial produtivo das hortaliças (Souza et al., 2008), sendo, portanto, fundamental a obtenção de mudas de alta qualidade.

Uma alternativa para a obtenção de mudas de qualidade é o uso de gongocomposto. O gongocomposto é uma biotecnologia que se baseia na atividade alimentar de diplópodes, conhecidos popularmente como gongolos ou piolhos-de-cobra. Estes organismos ao fragmentar os resíduos vegetais, produzem péletes fecais com diferentes características físico-químicas do material vegetal original, como por exemplo, a diminuição na relação carbono/nitrogênio (Thakur et al., 2011; Karthigeyan \& Alagesan, 2011; Anilkumar et al., 2012). Este processo forma um substrato com propriedades químicas, físicas e biológicas capazes de fornecer as condições necessárias ao desenvolvimento de hortaliças na fase inicial de muda, dispensando a necessidade da busca por formulação de misturas para compor um substrato, já que ele é de pronto uso (Antunes et al., 2016).

Com isso os restos culturais produzidos anualmente nas propriedades agrícolas podem ter um destino ambientalmente correto, servindo como matéria-prima de baixo custo na produção deste tipo de substrato (Silveira al., 2002; Medeiros et al., 2007; Araújo Neto et al., 2009). Dispensa-se também a necessidade do produtor adquirir substratos comerciais ou formular misturas.

Estudos sobre a produção deste substrato e sua eficiência são assuntos ainda incipientes no mundo, com pesquisas pontuais na Índia (Anilkumar et al.,
2012) e no Brasil (Antunes et al., 2016), as quais demonstram o potencial de produção de composto orgânico de excelente qualidade no desenvolvimento de plantas. Entretanto, a literatura especializada não revela até onde o tempo de decomposição do substrato influencia na sua qualidade e, consequentemente, no desempenho das mudas com ele obtidas. Ainda não se sabe se o tempo que o material vegetal é submetido a esta decomposição influencia na qualidade do substrato e, consequentemente, na qualidade das mudas.

Sabe-se que componentes orgânicos biodegradáveis sofrem sucessivas transformações, sob a ação de diversos grupos de microrganismos (Bettiol \& Camargo, 2000). Este processo se dá pela diferenciada velocidade de decomposição do material, segundo suas propriedades. Os açúcares, amidos e proteínas simples são decompostos primeiro; a seguir, há a decomposição da proteína bruta e da hemicelulose. Outros componentes, como a celulose, a lignina e as gorduras, são mais resistentes podendo, com o tempo, dar origem às substâncias orgânicas de estrutura química mais complexa, genericamente denominadas húmus (Miyasaka et al., 1983; Tibau, 1983; Igue, 1984). Ao longo deste processo a fragmentação dos resíduos em partes menores promove o aumento da superfície de contato, permitindo gradativamente o ataque microbiano (Antunes et al., 2016; Anilkumar et al., 2012), promovendo inclusive o aumento nos teores de nitrogênio, fósforo e potássio no material final (Anilkumar et al., 2012).

Considerando, portanto, que o tempo de decomposição pode melhorar as características do gongocomposto, o presente trabalho teve como objetivo avaliar desempenho agronômico da alface cultivar Vera sob sistema de produção orgânico, utilizando mudas produzidas neste substrato obtido em diferentes tempos de preparo.

\section{MATERIAL E MÉTODOS}

As mudas de alface crespa cultivar Vera foram produzidas em casa de vegetação do Sistema Integrado de Produção Agroecológica (SIPA - "Fazendinha 
Agroecológica km 47”), localizado no município de Seropédica-RJ, no período de 02 a 30 de maio de 2016. A altitude do local é de 33,0 m e o clima é classificado como Aw, com chuvas concentradas no período de novembro a março, com precipitação anual média de $1213 \mathrm{~mm}$ e temperatura média anual de $24,5^{\circ} \mathrm{C}$ (Cruz, 2005).

Utilizou-se bandejas de poliestireno expandido de 200 células a partir de substratos de gongocomposto gerado com diferentes tempos: 90 dias (T1); 125 dias (T2) e 180 dias (T3). Como parâmetro comparativo, também se utilizou o substrato SIPA ( $83 \%$ de vermicomposto, $15 \%$ de fino de carvão vegetal e $2 \%$ de torta de mamona, utilizando-se o critério volume/volume (Oliveira et al., 2011)). A matéria-prima utilizada para produção do gongocomposto, teve a composição a seguir: $40 \%$ de folhas secas de Bauhinia sp. (pata-de-vaca), 30\% de Paspalum notatum (grama batatais), 20\% de folhas de Musa sp. (bananeira) e $10 \%$ de papelão picado. O preparo dos resíduos e consumo pelo diplópode Trigoniulus corallinus estão descritos em Antunes et al. (2016). As características físico-químicas e físicas dos substratos estão contidas na Tabela 1 .

$\mathrm{O}$ vigor das mudas e estabilidade dos torrões foram determinadas, utilizando 10 mudas retiradas aleatoriamente das mesmas bandejas que forneceram as mudas transplantadas a campo. O vigor das mudas (VM) é uma metodologia adaptada de Franzin et al. (2005), que classificam como nota 1: ótimo vigor, acima de 5 folhas, altura maior que $5 \mathrm{~cm}$; nota 2: vigor bom, 4 a 5 folhas, altura maior que $5 \mathrm{~cm}$ com amarelado não proeminente; nota 3: amarelecimento notório, 4 a 5 folhas, tamanho até $5 \mathrm{~cm}$, porém com deficiência nutricional bem destacada; nota 4: deficiência nutricional, problemas na altura, número de folhas reduzido. A estabilidade do torrão (ET) é uma metodologia adaptada de Gruszynski (2002), que classifica como nota 1: $50 \%$ ou mais do torrão fica retido no recipiente na retirada da muda; nota 2: 30 a 50\% do torrão fica retido no recipiente na retirada da muda; nota 3: torrão destaca-se do recipiente, porém não permanece coeso; nota 4: o torrão é destacado completamente do recipiente e mais de $90 \%$ dele permanece coeso.

O experimento de campo foi conduzido em área experimental cujo solo pertence à ordem ARGISSOLO VERMELHO AMARELO, de baixa fertilidade natural (Neves et al., 2005) e que vem sendo cultivado com olerícolas. O resultado da análise química na profundidade de 0 - 20 centímetros, de acordo com a metodologia descrita por Embrapa (2005), foram as seguintes: matéria orgânica $=15,69 \mathrm{~g} \mathrm{~kg}^{-1} ; \mathrm{pH}=6,42 ; \mathrm{N}_{\text {total }}=1,0 \mathrm{~g} \mathrm{~kg}^{-1}$; $\mathrm{P}_{\text {disponivel }}=51,96 \mathrm{mg} \mathrm{dm}^{-3} ; \mathrm{K}^{+}=181 \mathrm{mg} \mathrm{dm}^{-3} ; \mathrm{Ca}^{+2}=$

Tabela 1 - Valores de potencial hidrogeniônico $(\mathrm{pH})$, condutividade elétrica $(\mathrm{CE})$, relação C/N, macronutrientes totais, percentual de macroporos, percentual de microporos, percentual de porosidade total, capacidade de retenção de água à tensão de $10 \mathrm{~cm}\left(\mathrm{CRA}_{10 \mathrm{~cm}}\right)$ e densidade volumétrica dos substratos utilizados na produção de mudas de alface crespa cultivar Vera

\begin{tabular}{|c|c|c|c|c|c|}
\hline \multirow{2}{*}{ Parâmetro } & & \multicolumn{4}{|c|}{ Substratos } \\
\hline & & T1 - 90 dias & $\mathrm{T} 2-125$ dias & $\mathrm{T} 3-180$ dias & T4 - SIPA \\
\hline \multirow[t]{2}{*}{ Físico-químico } & $\mathrm{pH}$ & 8,34 & 7,69 & 7,46 & 7,01 \\
\hline & $\mathrm{CE}\left(\mathrm{dS} \mathrm{m} \mathrm{m}^{1}\right)$ & 0,65 & 1,39 & 1,63 & 2,66 \\
\hline \multirow{6}{*}{ Químico } & $\mathrm{C} / \mathrm{N}$ & 18,98 & 16,51 & 15,06 & 16,66 \\
\hline & $\mathrm{C}\left(\mathrm{g} \mathrm{kg}^{-1}\right)$ & 379,03 & 357,20 & 352,33 & 276,20 \\
\hline & $\mathrm{P}\left(\mathrm{g} \mathrm{kg}^{-1}\right)$ & 1,35 & 1,57 & 2,18 & 5,43 \\
\hline & $\mathrm{K}\left(\mathrm{g} \mathrm{kg}^{-1}\right)$ & 6,50 & 7,32 & 7,31 & 8,21 \\
\hline & $\mathrm{Ca}\left(\mathrm{g} \mathrm{kg}^{-1}\right)$ & 28,19 & 31,68 & 36,91 & 14,60 \\
\hline & $\operatorname{Mg}\left(\mathrm{g} \mathrm{kg}^{-1}\right)$ & 4,85 & 5,36 & 6,05 & 7,00 \\
\hline \multirow{4}{*}{ Físico } & Macroporos (\%) & 30,17 & 29,26 & 24,63 & 28,31 \\
\hline & Microporos (\%) & 50,10 & 50,74 & 64,97 & 48,16 \\
\hline & $\mathrm{CRA}_{10 \mathrm{~cm}}$ & 25,05 & 25,37 & 32,48 & 24,08 \\
\hline & Densidade $\left(\mathrm{kg} \mathrm{m}^{-3}\right)$ & 236 & 323 & 221 & 366 \\
\hline
\end{tabular}


$3,71 \mathrm{cmol}_{\mathrm{c}} \mathrm{dm}^{-3} ; \mathrm{Mg}^{+2}=1,46 \mathrm{cmol}_{\mathrm{c}} \mathrm{dm}^{-3} ; \mathrm{Al}^{+3}=0,0 \mathrm{cmol}_{\mathrm{c}}$ $\mathrm{dm}^{-3} ; \mathrm{H}+\mathrm{Al}=2,19 \mathrm{cmol}_{\mathrm{c}} \mathrm{dm}^{-3}$.

O solo foi preparado com uma aração e duas gradagens de nivelamento e, em seguida, com auxílio de uma encateiradora acoplada ao trator, foram levantados os canteiros com $0,2 \mathrm{~m}$ de altura e $0,9 \mathrm{~m}$ de largura, com espaçamento entre canteiros de $0,30 \mathrm{~m}$. Foi realizada uma adubação orgânica 4 dias antes do transplantio utilizando 400 gramas de Bokashi Anaeróbico por $\mathrm{m}^{2}$, constituído de farelo de trigo ( $55 \%$ ) e torta de mamona (45\%), formulado e aplicado de acordo com a recomendação de Siqueira (2013). O Bokashi Anaeróbico apresentou as seguintes características químicas: $\mathrm{N}=32,6 \mathrm{~g} \mathrm{~kg}^{-1} ; \mathrm{P}=10,12 \mathrm{~g} \mathrm{~kg}^{-1} ; \mathrm{K}=11,82 \mathrm{~g}$ $\mathrm{kg}^{-1} ; \mathrm{Ca}=3,27 \mathrm{~g} \mathrm{~kg}^{-1} \mathrm{e} \mathrm{Mg}=4,70 \mathrm{~g} \mathrm{~kg}^{-1}$, de acordo com a metodologia descrita por Embrapa (2005).

O transplantio das mudas para os canteiros de produção foi realizado aos 28 dias após semeadura, em espaçamento de $30 \times 20 \mathrm{~cm}$, em blocos com quatro repetições. As parcelas foram constituídas por mudas de alface desenvolvidas na mesma época em quatro tipos de substratos. Cada parcela experimental no campo foi composta por 30 plantas, perfazendo uma área de $2,0 \mathrm{~m}^{2}$ com três linhas de plantio e 10 plantas por linha. Após sete dias do transplantio das mudas, foi colocada sobre os canteiros cobertura morta de Pennisetum purpureum Schum (capim elefante variedade Napier), formando uma camada uniforme e com espessura de cinco centímetros sobre os canteiros, a fim de evitar a mato-competição com as plantas de alface.

A irrigação foi realizada por fita gotejadora, com gotejadores espaçados a 0,2 metros entre si, com vazão comercial de $1,8 \mathrm{~L} \mathrm{~h}^{-1}$. O sistema foi montado em fileiras simples, constituído por uma linha de derivação de PVC de $50 \mathrm{~mm}$ e 3 linhas laterais com as fitas gotejadoras por canteiro. O monitoramento da necessidade hídrica da cultura foi realizado através da determinação da evapotranspiração de referência pelo método de PenmanMonteith-FAO 56 (PMF) (Allen et al., 1998), corrigida pelos coeficientes da cultura. Os dados meteorológicos foram fornecidos pelo Instituto Nacional de Meteorologia (INMET), a partir da estação denominada Ecologia Agrícola (RJ).

A colheita ocorreu aos 44 dias após o transplantio, através do corte das plantas rentes ao nível do solo. A parcela útil foi representada por oito plantas da fileira central. Foram avaliados os parâmetros de massa fresca comercial (g), diâmetro e altura da planta $(\mathrm{cm})$, número de folhas maiores que cinco centímetros e produtividade. Para estimativa da produtividade comercial utilizouse o índice de área útil do hectare cultivado ( $83 \%$ ), com densidade de plantio de 124.500 plantas ha ${ }^{-1}$, multiplicado pela massa fresca comercial. As plantas também foram classificadas conforme as Normas do Programa Brasileiro para Padronização da Horticultura (Hortibrasil, 2016), de acordo com o limite inferior e superior de massa fresca em gramas por planta (classes: $5 \leq 100 \mathrm{~g} ; 10=100 \mathrm{a}<150 \mathrm{~g} ; 15=150 \mathrm{a}<200 \mathrm{~g} ; 20$ $=200 \mathrm{a}<250 \mathrm{~g} ; 25=250 \mathrm{a}<300 \mathrm{~g} ; 30=300 \mathrm{a}<350$ $\mathrm{g}$; e assim sucessivamente até classe $100 \geq 1000 \mathrm{~g}$ ).

Para a análise dos dados foi realizada avaliação da homogeneidade das variâncias dos resíduos pelo teste de Bartlett e da normalidade pelo teste de ShapiroWilk, a $5 \%$ de probabilidade, utilizando o programa livre R. Os dados da avaliação de mudas foram posteriormente submetidos ao teste de Scott-Knott a 5\% e os dados da alface produzida a campo submetidos ao teste de Dunnett a $5 \%$.

\section{RESULTADOS E DISCUSSÃO}

Durante o desenvolvimento da cultura observouse que a temperatura média variou de 15,9 a $27,3{ }^{\circ} \mathrm{C}$. A temperatura máxima registrada no período do experimento foi de $33,4{ }^{\circ} \mathrm{C}$ e a mínima registrada foi de $10,1^{\circ} \mathrm{C}$. A evapotranspiração média de referência foi de $2,77 \mathrm{~mm}$ e a precipitação registrada no período totalizou $120 \mathrm{~mm}$. De acordo com Filgueira (2003), a temperatura máxima do ar tolerada pela alface é de $30^{\circ} \mathrm{C}$ e a mínima é de $6^{\circ} \mathrm{C}$. Portanto, as condições climáticas durante o período em que se conduziu o experimento foram consideradas normais, permitindo bom desempenho da cultura.

A massa fresca comercial do tratamento $\mathrm{T} 1$ apresentou menor peso médio comparado à referência, com 173,33 gramas por planta (Tabela 3). Este resultado pode ser atribuído à qualidade das mudas produzidas neste substrato, as quais tiveram seu desenvolvimento inferior possivelmente influenciado pela insuficiência de nutrientes disponíveis, que por se tratar de um substrato orgânico, não foi capaz de mineralizar e disponibilizar no período de 28 dias todos os nutrientes que as mudas demandariam. Isso reforça-se com os valores das mudas do tratamento $\mathrm{T} 1$, que foram avaliadas quanto ao seu vigor de muda (VM) e estabilidade do 
torrão (ET), as quais receberam notas médias de 3,38 e 1,43 , respectivamente (Tabela 2). Este resultado corrobora com Rodrigues et al. (2010), que destacam a importância da qualidade da muda na cadeia produtiva de hortaliças, cuja a formação é uma das fases mais importantes para o ciclo da cultura, influenciando diretamente no desempenho final da planta, tanto do ponto de vista nutricional como produtivo, no qual a muda transplantada com qualidade comprometida, demora mais tempo para restabelecer-se.

Além disso, observou-se semelhança dos substratos de gongocomposto produzidos com 125 e 180 dias com o substrato à base de vermicomposto - T4 (Tabela 3). Os resultados da massa fresca comercial do tratamento $\mathrm{T} 1$ obtidos neste experimento foram semelhantes ao verificado por Ferreira et al. (2014), os quais avaliaram o desempenho agronômico da alface $\mathrm{cv}$. Vera em cultivo orgânico no município de Rio Branco-AC e obtiveram no tratamento com cobertura morta de capim, peso médio de massa fresca comercial de 173,90 gramas. Farias et al. (2017) produziram alface cv. Babá de verão

Tabela 2 - Valores médios de vigor de muda (VM) e estabilidade do torrão (ET) das mudas de alface crespa cv. Vera, produzidas em substratos orgânicos na Fazendinha Agroecológica do Km 47, Seropédica-RJ

\begin{tabular}{ccc}
\hline Tratamentos & Vigor da muda & Estabilidade do torrão \\
\hline T1 - 90 dias & $3,38 \mathrm{a}$ & $1,43 \mathrm{c}$ \\
T2 - 125 dias & $1,08 \mathrm{~b}$ & $1,33 \mathrm{c}$ \\
T3 - 180 dias & $1,23 \mathrm{~b}$ & $3,03 \mathrm{~b}$ \\
T4 - SIPA & $1,12 \mathrm{~b}$ & $3,77 \mathrm{a}$ \\
CV\% & 19,42 & 17,65 \\
\hline
\end{tabular}

Médias seguidas pela mesma letra na coluna não diferem pelo teste de Scott-Knott ao nível de 5\% de probabilidade. adubadas com esterco bovino e obtiveram aos 40 dias após o cultivo em canteiros, um peso de massa fresca da parte aérea de 295,1 g, média que se aproxima dos resultados encontrados neste trabalho para os tratamentos T2, T3 e T4 (Tabela 3).

Apesar de não ter ocorrido diferença estatística na massa fresca comercial entre os tratamentos $\mathrm{T} 2$, $\mathrm{T} 3$ e T4, houve uma pequena diferença em seus pesos médios, onde as plantas do tratamento T2 apresentaram 33,14 gramas a menos no seu peso médio quando comparado ao tratamento controle T4 (Tabela 3). Tal diferença pode ser explicada pela estabilidade do torrão (ET) das mudas oriundas do tratamento T2, que tiveram médias de nota 1,33 , de forma semelhante ao tratamento T1 (Tabela 2), com metade ou mais do substrato retido na bandeja, o que refletiu no transplantio com raízes parcialmente nuas, proporcionando assim uma demora maior no pegamento destas mudas.

Lima et al. (2004) buscando verificar o comportamento da alface Vera e Verônica em dois espaçamentos, na região de Ribeirão Preto (SP), durante o outono, obtiveram valores médios de massa fresca comercial no mesmo espaçamento adotado neste experimento (30×20 cm), de 263,34 gramas para a cultivar Vera, cujo sistema de produção adotado foi convencional, contando ainda com a adição de 80 toneladas por hectare de esterco bovino juntamente aos fertilizantes sintéticos. Neste sentido, os tratamentos T2, T3 e T4, apresentam valores médios relativamente superiores, com 15,90, 45,03 e 49,04 gramas a mais (Tabela 3) se comparado ao sistema convencional adotado pelos autores supracitados, respectivamente, demonstrando que a adubação orgânica vegetal por meio do Bokashi é eficiente e possibilita a diminuição dos inputs no sistema agrícola, gerando economia para o produtor e diminuição

Tabela 3. Valor médio e erro padrão para os parâmetros de massa fresca comercial, diâmetro (cm), altura de planta $(\mathrm{cm})$, número de folhas $\geq 5 \mathrm{~cm}$, classe comercial e produtividade estimada de alface crespa cv. Vera, produzida sob cultivo orgânico na Fazendinha Agroecológica do km 47, Seropédica-RJ

\begin{tabular}{|c|c|c|c|c|c|c|}
\hline Tratamentos & Massa fresca comercial & Diâmetro & Altura & $N^{o}$ folhas & Classe & Produtividade \\
\hline & $\left(\right.$ g planta $\left.{ }^{-1}\right)$ & - & - & $(\geq 5 \mathrm{~cm})$ & comercial & $\left(\mathrm{Mg} \mathrm{ha}^{-1}\right)$ \\
\hline T1-90 dias & $173,3^{*} \pm 8,91$ & $25,1 \pm 0,49$ & $23,6 * \pm 0,46$ & $14,2 * \pm 0,39$ & $15,1 * \pm 0,94$ & $21,6^{*} \pm 1,11$ \\
\hline $\mathrm{T} 2-125$ dias & $279,2 \pm 10,10$ & $29,7 \pm 0,80$ & $28,6 \pm 0,31$ & $18,7 \pm 0,33$ & $25,8 \pm 0,97$ & $34,8 \pm 1,26$ \\
\hline T3-180 dias & $308,4 \pm 8,95$ & $32,8 \pm 0,67$ & $30,5 \pm 0,34$ & $19,3 \pm 0,44$ & $28,6 \pm 0,85$ & $38,4 \pm 1,15$ \\
\hline T4-SIPA & $312,4 \pm 10,44$ & $31,0 \pm 0,76$ & $29,3 \pm 0,32$ & $19,0 \pm 0,29$ & $29,1 \pm 1,03$ & $38,9 \pm 1,30$ \\
\hline $\mathrm{CV}(\%)$ & 7,90 & 8,53 & 2,84 & 5,25 & 7,80 & 7,90 \\
\hline
\end{tabular}

*Difere do controle pelo teste de Dunnett a $5 \%$. 
dos riscos ambientais por lixiviação de nutrientes oriundos da fertilização química.

O diâmetro médio das plantas variou entre 25,1 e 32,8, sem diferenças em relação a referência (Tabela $3)$. Essas médias superam as obtidas por Almeida et al. (2008), que avaliaram o potencial de dois fertilizantes de leguminosas mucuna-cinza (Mucuna pruriens) e gliricídia (Gliricidia sepium), como fontes alternativas de N, obtendo valores médios de $27,2 \mathrm{~cm}$ na primeira colheita e 29,6 cm na segunda colheita. Silva et al. (2000), avaliando o comportamento de cultivares de alface em diferentes espaçamentos, obtiveram maiores diâmetros de plantas quando cultivadas nos maiores espaçamentos $(20 \times 30,25 \times 30$ e $30 \times 30 \mathrm{~cm})$. Os autores relatam que maiores espaçamentos diminuem a competição entre plantas por água, luz e nutrientes, proporcionando plantas com maiores diâmetros.

A altura das plantas diferiu estatisticamente entre os tratamentos, variando de 23,63 a 30,48 cm, havendo diferenças entre o tratamento $\mathrm{T} 1 \mathrm{e}$ a referência (Tabela 3). Aquino et al. (2014) avaliaram a influência de diferentes ambientes e espaçamentos na produção e tolerância ao pendoamento da alface-romana, obtendo média de altura de plantas no campo aberto de $29,97 \mathrm{~cm}$, média semelhante aos tratamentos T2, T3 e T4. Segundo Luz et al. (2009), a altura das plantas pode ser considerada uma característica de verificação de tolerância ao pendoamento, contudo não foram observadas mudanças na aparência ou no formato comercial das plantas que indicassem início de pendoamento.

As características relacionadas com o porte das plantas, tais como o diâmetro e a altura, podem fornecer informações importantes no que se refere ao acondicionamento das plantas colhidas, pois a principal forma de transportá-las ocorre por meio de caixas plásticas ou de madeira (Sala \& Costa, 2012). Neste sentido, plantas com maiores dimensões e alturas podem ser danificadas nos processos de acondicionamento e transporte, o que pode comprometer a qualidade comercial do produto (Suinaga et al., 2013), sendo acondicionadas para comercialização 18 unidades por caixa.

O número de folhas é de grande importância para o produtor, pois é o produto final que será enviado à mesa do consumidor ou beneficiado (minimamente processado). Verifica-se que houve diferença significativa em relação a esta variável, com o tratamento $\mathrm{T} 1$ apresentando um número médio de 14,18 folhas, número este inferior à referência, que apresentou 19,0 (Tabela $3)$. Esses resultados são superiores aos alcançados por Meneses et al. (2016), os quais avaliaram o efeito de diferentes coberturas do solo no crescimento e produtividade de plantas alface crespa - cultivar Vera, registrando valores médios de 17,56 folhas com solo coberto por palha de capim-elefante (Pennisetum purpureum). O maior número de folhas e qualidade das plantas são dependentes da adição de cobertura morta sobre o solo, a qual é capaz de modificar as condições em que as sementes das plantas espontâneas germinam, dificultando a emergência pela menor incidência de luz, menor amplitude térmica do solo entre dia e noite e pela barreira física imposta pelas coberturas mortas (Carvalho et al., 2005).

As maiores produtividades estimadas foram proporcionadas pelos tratamentos $\mathrm{T} 2, \mathrm{~T} 3 \mathrm{e} \mathrm{T} 4$, variando de 34,78 a $38,89 \mathrm{Mg} \mathrm{ha}^{-1}$ (Tabela 3). Estes resultados são semelhantes ao obtido por Oliveira et al. (2006), os quais avaliaram a produção de alface crespa cv. Vera em sistema de plantio direto sobre cobertura viva de gramínea e leguminosa, obtendo produtividade média de $39 \mathrm{Mg} \mathrm{ha}^{-1}$. De forma geral, os tratamentos T2, T3 e T4 superam as médias de produtividade encontradas em outros trabalhos para a mesma cultivar, que registraram 24,94 $\mathrm{Mg} \mathrm{ha}^{-1} \mathrm{em}$ Alta Floresta - MT (Santi et al., 2010) e 21,25 Mg ha-1 em Rio Branco-AC (Simões et al., 2015).

A produtividade encontrada por Simões et al. (2015), que buscaram avaliar o efeito de diferentes condicionadores na qualidade da muda de alface orgânica, foi semelhante ao tratamento $\mathrm{T} 1$, que apresentou uma produtividade estimada de 21,58 $\mathrm{Mg} \mathrm{ha}^{-1}$ (Tabela 3). De certa maneira, o tratamento $\mathrm{T} 1$ mesmo sendo inferior, supera a produtividade estimada por Freire et al. (2013), que para o estado do Rio de Janeiro está entre 15 a $20 \mathrm{Mg} \mathrm{ha}^{-1}$ de alface fresca, demonstrando que os níveis nutricionais obtidos neste experimento foram adequados por meio da adubação orgânica vegetal via Bokashi anaeróbico.

\section{CONCLUSÕES}

Os dados obtidos neste trabalho confirmam que a qualidade da muda transplantada a campo foi capaz de influenciar no desempenho produtivo da cultura da alface. 
Todos os tratamentos apresentaram valores médios similares para todos os parâmetros avaliados, com exceção do tratamento T1-90 dias, que foi inferior em todos valores médios, devido à qualidade das mudas serem inferiores quando comparada aos dos demais tratamentos.

Efetivamente o gongocomposto pode ser aproveitado como substrato, dependendo do tempo em que os resíduos forem submetidos à ação dos diplópodes, propiciando a formação de mudas de alface de superior qualidade, com reflexo direto no desempenho da cultura.

\section{LITERATURA CITADA}

ALLEN, R.G.; PEREIRA, L.S.; RAES, D.; SMITH, M. Crop evapotranspiration - Guidelines for computing crop water requeriments. Rome: FAO, 1998. 308p.

ALMEIDA, M.M.T.B; LIXA, A.T.; SILVA, E.E.; AZEVEDO, P.H.S.; DE-POLLI, E.; RIBEIRO, R.L.D. Fertilizantes de leguminosas como fontes alternativas de nitrogênio para produção orgânica de alface. Pesquisa Agropecuária Brasileira, Brasília, v.43, n.6, p.675-682, jun. 2008.

ANILKUMAR, C.; IPE, C.; BINDU, C.; CHITRA, C.R.; MATHEW, P.J.; KRISHNAN, P.N. Evaluation of millicompost versus vermicompost. Current Science, v.103, n.2, 25 july 2012.

ANTUNES, L.F.S.; SCORIZA, F.N.; SILVA, D.G.; FERNANDES, M.E.C. Production and efficiency of organic compost generated by millipede activity. Ciência Rural, Santa Maria-RS, v.46, n.5, p.815-819, 2016. http://dx.doi.org/10.1590/0103$8478 \mathrm{cr} 20150714$.

AQUINO, C.R.; SEABRA JUNIOR, S.; CAMILI, E.C.; DIAMENTE, M.S.; PINTO, E.S.C. Produção e tolerância ao pendoamento de alface-romana em diferentes ambientes. Revista Ceres, Viçosa, v.61, n.4, p.558-566, 2014. http://dx.doi.org/ 10.1590/0034-737X201461040016.

ARAÚJO NETO, S.E.; AZEVEDO, J.M.A.; GALVÃO, R.O.; OLIVEIRA, E.B.L.; FERREIRA, R.L.F. Produção de muda orgânica de pimentão com diferentes substratos. Ciência Rural, v.39, n.5, 2009 .
BETTIOL, W.; CAMARGO, O. A. Impacto ambiental do uso do lodo de esgoto. Jaguariuna: EMBRAPA Meio Ambiente, 2000. $312 \mathrm{p}$.

CARVALHO, J.E.; ZANELLA, F.; MOTA, J.H.; LIMA, A.L.S. Cobertura morta do solo no cultivo da alface cv. Regina 2000, em Ji-Paraná/ RO. Ciência Agrotecnologia, v.1, n.29, p.935-939, 2005.

CRUZ, F.A. Instalação e calibração de lisímetro de pesagem e determinação da evapotranspiração de referência para a região de Seropédica-RJ. 2005. 65p. (Dissertação, mestrado em Fitotecnia), Universidade Federal Rural do Rio de Janeiro, Seropédica-RJ, 2005.

FARIAS, D.B.S.; LUCAS, A.A.T.; MOREIRA, M.A.; NASCIMENTO, L.F.A.; SÁ FILHO, J.C.F. Cobertura do solo e adubação orgânica na produção de alface. Revista Ciências Agrárias, v.60, n.2, p.173-176, abr./jun. 2017. http://dx.doi.org/10.1590/S0034737 X2013000400019.

DINIZ, K.A.; GUIMARÃES, S.T.M.R.; LUZ, J.M. Q. Húmus como substrato para a produção de mudas de tomate, pimentão e alface. Bioscience Journal, Uberlândia, v.22, n.3, p.63-70, 2006.

FERREIRA, R.L.F; ALVES, A.S.S.C.; ARAÚJO NETO, S.E.; KUSDRA, J.F.; REZENDE, M.I.F.L. Produção orgânica de alface em diferentes épocas de cultivo e sistemas de preparo e cobertura de solo. Bioscience Journal, Uberlandia, v.30, n.4, p.1017-1023, 2014.

FILGUEIRA, F.A.R. Novo manual de olericultura: agrotecnologia moderna na produção e comercialização de hortaliças. 2.ed. Viçosa: UFV. 2003. 412 p.

FRANZIN, S.M.; MENEZES, N.L.; GARCIA, D.C.; SANTOS, O.S. Efeito da qualidade das sementes sobre a formação de mudas de alface. Horticultura Brasileira, Brasília, v.23, n.2, p.193-197,2005. 
FREIRE, L.R.; BALIEIRO, F.C.; ZONTA, E.; ANJOS, L.H.C.; PEREIRA, M.G.; LIMA, E.; GUERRA, J.G.M.; FERREIRA, M.B.C; LEAL, M.A.A.; CAMPOS, D.V.B.; POLIDORO, J.C. Manual de calagem e adubação do Estado do Rio de Janeiro. Brasília, DF: EMBRAPA, Seropédica, RJ. Editora Universidade Rural, 2013.430p.

GRUSZYNSKI, C. Resíduo agro-industrial "casca de tungue" como componente de substrato para plantas. Porto Alegre: UFRGS. 2002. 41p. (Tese mestrado).

HERNANDEZ, O.L.; HUELVA, R.; GURIDI, F.; OLIVARES, F.L.; CANELLAS, L.P. Humatos isolados de vermicomposto como promotores de crescimento em cultivo orgânico de alface.

Revista Ciências Técnicas Agrícolas, v.22, n.1, San José de las Lajas jan.-mar. 2013.

HORTIBRASIL. Instituto Brasileiro de Qualidade em Horticultura. Programa Brasileiro para a Modernização da Horticultura. Disponível em <http://www.hortibrasil.org.br/ classificacao/alface/alface.html $>$. Acesso em 17 julho de 2016.

IGUE, K.; PAVAN, M.A. Uso eficiente de adubos orgânicos. In: SIMPÓSIO SOBRE FERTILIZANTES NAAGRICULTURA BRASILEIRA, 1984, Brasília. Anais... p.383-418.

KARTHIGEYAN, M.; ALAGESAN, P. Millipede composting: a novel method for organic waste recycling. Recent Research in Science and Technology, v.3, n.9, p.62-67, 2011. Disponível em: < http://recent-science.com/ index.php/rrst/article/viewArticle/8591 > . Acesso em 17 mai. 2016.

LIMA, A.A.; MIRANDA, E.G.; CAMPOS, L.Z.O.; CUZNATO JÚNIOR, W.H.; MELO, S.C.;

CAMARGO, M.S. Competição das cultivares de alface Vera e Verônica em dois espaçamentos.

Horticultura Brasileira, Brasília, v.22, n.2, p.314-316, 2004.

LUZ, A.O.; SEABRA JÚNIOR S.; SOUZA, S.B.S.; NASCIMENTO, A.S. Resistência ao pendoamento de genótipos de alface em ambientes de cultivo. Agrarian, v.2, p.71-82, 2009.
MEDEIROS, D.C.; LIMA, B.A.B.; BARBOSA, M.R.; ANJOS, R.S.B.; BORGES, R.D.; CAVALCANTE NETO, J.G.; MARQUES, L.F. Produção de mudas de alface com biofertilizantes e substratos. Horticultura Brasileira, v.25, p.433436, 2007.

MENESES, N.B.; MOREIRA, M.A.; SOUZA, I.M.; BIANCHINI, F.G. Crescimento e produtividade de alface sob diferentes tipos de cobertura do solo. Revista Agro@mbiente On-line, v.10, n.2, p.123129, 2016. http://dx.doi.org/10.18227/19828470ragro.v10i2.3009.

MIYASAKA, S.; CAMARGO, O.A.; CAVALERI, P.A. Adubação orgânica, adubação verde e rotação de culturas no Estado de São Paulo. Campinas, 1983. 138p.

NEVES, M.C.P.; GUERRA, J.G.M.; CARVALHO, S.R.; RIBEIRO, R.L.D.; ALMEIDA, D.L. Sistema Integrado de Produção Agroecológica ou Fazendinha Agroecológica do Km 47. p.149-150. In: Aquino et al. (2005). Agroecologia: princípios e técnicas para uma agricultura orgânica sustentável. Editores técnicos: Adriana Maria de Aquino, Renato Linhares de Assis. - Brasília, DF: Embrapa Informação Tecnológica, 2005. 517p.

OLIVEIRA, E.A.G.; RIBEIRO, R.L.D.; GUERRA, J.G.M.; LEAL, M.A.A.; ESPÍNDOLA, J.A.A.; ARAÚJO, E.S. Substrato produzido a partir de fontes renováveis para a produção orgânica de mudas de hortaliças. Seropédica: Embrapa Agrobiologia, (Boletim técnico), 2011. 4p.

OLIVEIRA, N.G.; DE-POLLI, H.; ALMEIDA, D.L.; GUERRA, J.G.M. Plantio direto de alface adubada com "cama" de aviário sobre coberturas vivas de grama e amendoim forrageiro. Horticultura Brasileira, v.24, p.112-117, 2006.

PEREIRA, A.R.; ANGELOCCI, L.R.; SENTELHAS, P.C. Agrometeorologia: fundamentos e aplicações práticas. Ed. Guaíba: Agropecuária, 2002. 478p.

RODRIGUES, E.T; LEAL, P.A.M.; COSTA, E.; PAULA, T.S.; GOMES, V.A. Produção de mudas de tomateiro em diferentes substratos e recipientes em ambiente protegido.

Horticultura Brasileira, v.28, p.483-488, 2010. http://dx.doi.org/10.1590/S010205362010000400018. 
SALA, F.C.; COSTA, C.P. Retrospectiva e tendência da alfacicultura brasileira. Horticultura Brasileira, v.30, p.187-194, 2012. http://dx.doi.org/ 10.1590/S0102-05362012000200002.

SANTI, A.; CARVALHO, M.A.C.; CAMPOS, O.R.; SILVA, A.F.; ALMEIDA, J.L.; MONTEIRO, S. Ação de material orgânico sobre a produção e características comerciais de cultivares de alface. Horticultura Brasileira, v.28, p.87-90, 2010. http://dx.doi.org/10.1590/S0102-05362010000100016.

SILVA, V.F.; NETO, F.B.; NEGREIROS, M.Z.; PEDROSA, J.F. Comportamento de cultivares de alface em diferentes espaçamentos sob temperatura e luminosidade elevadas. Horticultura

Brasileira, v.18, p.183-187, 2000.

SILVEIRA, E.B.; RODRIGUES, V.J.L. B.; GOMES, A.M.A.; MARIANO, R.L.R.; MESQUITA, J.C.P. Pó de coco como substrato para produção de mudas de tomateiro. Horticultura Brasileira, v.20, p.211216, 2002.

SIMÕES, A.C.; ALVES, G.K.E.B.; FERREIRA, R.L.F.; ARAUJO NETO, S.E. Qualidade da muda e produtividade de alface orgânica com condicionadores de substrato. Horticultura Brasileira, v.33, p.521-526, 2015. DOI - http:// dx.doi.org/10.1590/S0102-053620150000400019.
SIQUEIRA, A.P.P. Bokashi: adubo orgânico fermentado. Niterói: Programa Rio Rural, 2013. $16 \mathrm{p}$.

SOUZA, S.R.; FONTINELE, Y.R.; SALDANHA, C.S.; ARAÚJO NETO, S.E.; KUSDRA, J.F. Produção de mudas de alface com o uso de substrato preparado com cropólitos de minhoca. Ciência e Agrotecnologia, v.32, n.1, p.115$121,2008$.

SUINAGA, F.A.; BOITEUX, L.S; CABRAL, C.S.; RODRIGUES, C.S. Desempenho produtivo de cultivares de alface crespa. Boletim de Pesquisa e Desenvolvimento. Brasília, DF: Embrapa, 2013.

THAKUR, P.C.; SHAILENDRA, P.A.; SINHA, K. Comparative study of characteristics of biocompost produced by millipedes and earthworms. Pelagia Research Library. Advances in Applied Science Research, v.2, n.3, p.94-98, 2011.

TIBAU, A.O. Matéria orgânica e fertilidade do solo. $2^{a}$. ed. São Paulo: Nobel,1983. 220p.

Recebido para publicação em 4/12/2017 e aprovado em 10/9/2018. 